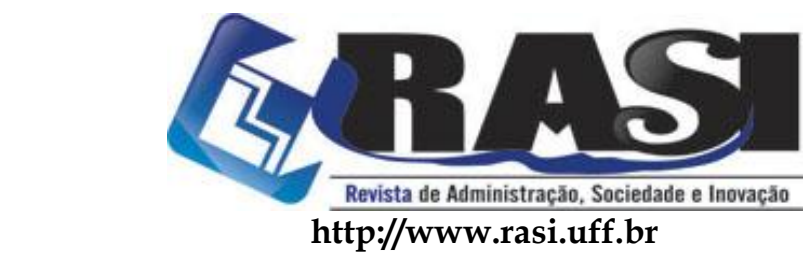

RASI, Volta Redonda/RJ, v. 2, n. 2, pp. 132-146, jul./dez. 2016

\title{
Mobilidade Social no Município de Quissamã (RJ): As Riquezas do Petróleo e os Problemas Contemporâneos.
}

Leilson Lyra

\begin{abstract}
RESUMO
No Brasil atual, o turbulento contexto político, econômico e social tem sido terra fértil para o exame das práticas de gestão. Assim, o presente artigo tem por propósito investigar a realidade socioeconômica_no município de Quissamã (RJ) em conexão com a expansão dos recursos financeiros advindos do petróleo, que abasteceram os cofres públicos a partir de 1997. Para tanto, fez-se revisão bibliográfica e análise quantitativa de dados, fruto de pesquisa a documentos públicos da prefeitura. Nesta etapa, foram identificados os mecanismos de gestão e aplicação dos recursos originados no petróleo, como principais promotores do desenvolvimento local. Adicionalmente, foi estabelecida análise comparada entre Quissamã (RJ) e o município vizinho Conceição de Macabu (RJ), visto que estes mantêm características territoriais e demográficas semelhantes. A despeito de Conceição não receber recursos do petróleo nos patamares de Quissamã, apresentou melhores índices de desenvolvimento. De resultado, verificou-se aumento da concentração de renda e a constatação de que os recursos públicos não geraram benefícios mais estruturantes para a população. Acredita-se que o debate proposto possa contribuir para o aperfeiçoamento das ações governamentais, restando salientar a necessidade de se aprofundar o que ora se discute, estabelecendo-se novos caminhos, num processo de melhoria da gestão de recursos públicos.
\end{abstract}

PALAVRAS CHAVE: Royalties. Social. Desenvolvimento.

\section{Social Mobility in the City of Quissamã (RJ): The Riches of Oil and Contemporary Problems}

\begin{abstract}
The turbulent political, economic and social context of today's Brazil has been a fertile soil for the management practices. This article aims to investigate the socioeconomic reality in the city of Quissamã (RJ) in connection with the expansion of the oil wealth which has been filling the public purse since 1997. For this purpose, bibliographic review has been conducted, as well a quantitative data analysis that resulted from research on public documents of city hall. Examples of the mechanisms of management and the use of financial resources originating from oil as the main promoters of local development were identified. Additionally, a comparative analysis between the city of Quissamã (RJ) and the neighboring city of Conceição de Macabu (RJ) was made, due to two cities having similar territorial and demographic characteristics. Although Conceição has not received financial resources from oil at the same level as Quissamã, it presented better development indexes. As a result, it was ascertained that there was an increase of income concentration and that the public resources have not created more structural benefits to the population. It is believed that the proposed study can contribute to the process improvement of governmental actions, emphasizing the need to deepen the current discussion, establishing new paths, in a process of improving public resource.
\end{abstract}

KEYWORDS Royalties. Social. Development.

\section{Q Universidade Uluminense}

R. Desembargador Ellis Hermydio Figueira, 783, Bloco A, sl. 218, Aterrado. 27213-415 - Volta Redonda, RJ - Brasil

www.uff.br

Copyright (c) 2016 RASI. Todos os direitos, até mesmo de tradução, são reservados. É permitido citar parte de artigos sem autorização prévia, desde que seja identificada a fonte. 


\section{Mobilidade Social no Município de Quissamã (RJ): As Riquezas do Petróleo e os Problemas Contemporâneos.}

\section{Introdução}

Este estudo faz uma análise do desenvolvimento socioeconômico no município de Quissamã, identificando os entraves que afetam sua ascensão. Situado ao Norte do Estado do Rio de Janeiro, região que recebe as maiores compensações financeiras advindas da produção e exploração de petróleo (royalties), possui os atrativos capazes de gerar crescimento populacional e econômico acelerados, a exemplo de municípios vizinhos como Macaé (RJ) e Campos (RJ). No entanto, nota-se que os avanços não tem refletido o potencial identificado para Quissamã, o que tratar-se-á ao longo deste artigo.

O censo demográfico realizado pelo Instituto Brasileiro de Geografia e Estatística (IBGE), realizado em 2010, revelou que a população do município era de 20.244 pessoas, distribuídas numa extensão territorial de $713 \mathrm{~km}^{2}$. Relacionando-se o número de habitantes com sua extensão territorial, percebe-se baixa densidade demográfica, sendo esta de 28,40 habitantes por quilômetros quadrados. Quando analisados os altos volumes de recursos recebidos no município em face de sua densidade demográfica, observa-se uma das maiores rendas per capitas do Brasil.

Diante de uma maior disponibilidade de verbas e consequente dinamização da cadeia produtiva local, espera-se melhores resultados nos indicadores de desenvolvimento e na participação popular, além de avanços nas instâncias políticas e públicas. Para isso é preciso que haja uma análise apurada de modo a compreender quais são as dificuldades que tem impedido o desenvolvimento em geral do município.

A caracterização metodológica desta pesquisa é de natureza exploratória, uma vez que o problema é identificado, classificado e definido pela pesquisa com base no levantamento bibliográfico que a norteia. Também é quantitativa, posto que se levantam dados, sendo analisados num interstício de 2004 a 2013, onde a riqueza de informações é abundante, como também o são os índices oficiais de desenvolvimento regional. Quanto ao uso dos recursos, foram utilizados relatórios, balancetes, planilhas, leis entre outros de modo a identificar os agentes de controle social vinculados à comunidade local, tais como: associações e ONGs que integram os canais de participação nas decisões locais, além dos conselhos deliberativos.

Quanto à sua estrutura, além da introdução, o estudo está organizado da seguinte forma: inicialmente é apresentado o referencial teórico. Neste espaço, autores ligados à temática lançam suas ideias e propõem novas reflexões. A seguir, passa-se ao desenvolvimento, no qual é enfatizado o contexto de Quissamã, ou seja, a realidade das receitas do petróleo para o município. Após, apresenta-se o mapa socioeconômico local sinalizado pelos índices de desenvolvimento econômico e social, que revelam os problemas contemporâneos enfrentados pela sociedade e por fim, apresentam-se as conclusões. As técnicas aplicadas para junção dos dados e análise dos resultados obtidos é apresentada na metodologia.

Assim, espera-se contribuir para o aperfeiçoamento do debate em torno da aplicação dos royalties pelos municípios produtores de petróleo, bem como para enriquecer as discussões quanto à construção de políticas públicas que, de fato, venham gerar melhores e maiores níveis de desenvolvimento. 


\title{
2. Referencial Teórico
}

Municípios como o de Quissamã, dada sua localização, são considerados pela legislação vigente, como sendo produtores de petróleo. Estes viram seus orçamentos crescerem exponencialmente com a chegada das rendas oriundas das atividades petrolíferas, especialmente por volta dos anos 2000. Relatórios internos demonstram que entre 2004 e 2013, ou seja, em aproximadamente dez anos, os cofres públicos municipais receberam $\mathrm{R} \$ 980.557 .229,81$ - isto sem levar em consideração, as aplicações financeiras e o repasse do Estado. Tal abundância é sinalizada da seguinte forma:

\begin{abstract}
As prefeituras dos municípios produtores, principalmente, dispõem de recursos milionários adicionais aos seus orçamentos, oriundos dos royalties e participações especiais, repassados pela Petrobras. Esses recursos proporcionam uma grande capacidade de investimento percapita, que os coloca entre os de maiores possibilidades de investimentos públicos no país (Cruz, Piquet e Vilani, 2013, p. 149).
\end{abstract}

Corroborando esse panorama, o estudo feito pelo Tribunal de Contas do Estado do Rio de Janeiro (TCE-RJ) (2002) mostrou que Quissamã ocupava posição privilegiada junto aos demais municípios da mesorregião Norte do Estado do Rio de Janeiro, conforme Tabela 1.

Tabela 1 - maiores recebedores de royalties - municípios do Norte do Estado do Rio

\begin{tabular}{clr}
\hline N. & \multicolumn{1}{c}{ Município } & Receita Total 2001 \\
\hline 1 & Campos dos Goytacazes & 381.114 .850 \\
2 & Macaé & 229.711 .487 \\
3 & Quissamã & 69.788 .673 \\
4 & São João da Barra & 36.754 .380 \\
5 & São Fidelis & 27.859 .323 \\
6 & Capapebus & 26.273 .085 \\
7 & São Francisco do Itabapoana & 24.597 .329 \\
8 & Cardoso Moreira & 15.203 .170 \\
9 & Conceição de Macabu & 15.187 .326 \\
\hline
\end{tabular}

Fonte: Elaboração própria - informações do TCE-RJ, 2002.

Percebe-se que Quissamã figurava como terceiro maior arrecadador de sua região. Com o passar dos anos e da crescente divulgação de dados públicos oficiais, tornou-se de domínio geral, notadamente de sua população local, que se tratava de um município rico em receitas oriundas do petróleo. Porém, a questão central a ser levantada passava pela democratização e eficiência no uso desses recursos, visto que as demandas da população também cresciam.

Nesta perspectiva, Brasil (1988) estabeleceu em seu texto no Art. $6^{\circ}$ que: "são direitos sociais, a educação, a saúde, o trabalho, o lazer, a segurança, a previdência social, a proteção à maternidade e à infância, a assistência aos desamparados, na forma desta constituição".

Diante deste dispositivo constitucional e do ambiente de transformações e de pressão popular, agigantou-se ainda mais a tarefa exercida pelos gestores públicos que 
passaram a assumir a partir de então, a responsabilidade de suprir as carências da sociedade, conjuntamente ao aperfeiçoamento e fortalecimento da democracia. Sem se descuidarem, evidentemente do rigor fiscal imputado aos novos tempos.

Aqui é importante destacar o caráter regulador e fiscalizador trazidos ao seio da administração pública pela Lei de Responsabilidade Fiscal, Brasil (2000). Este comando legal estabeleceu novos tempos para o gestor público, uma vez que as regras ali introduzidas ou aperfeiçoadas de legislações anteriores procuraram, dentre outros aspectos, promover à transparência na gestão fiscal, através do incentivo a participação da comunidade. Veja o que se destaca no art. 48, Brasil (2000):

A transparência da gestão fiscal é tratada na Lei como um princípio de gestão, que tem por finalidade, entre outros aspectos, franquear ao público acesso às informações relativas às atividades financeiras do Estado e deflagrar, de forma clara e previamente estabelecida, os procedimentos necessários à divulgação dessas informações (Cruz, Vicari Junior, Glock, Herzmann e Tremel, 2006, p. 188).

Ao citar Brasil (2000), é preciso contextualizar a cena pública brasileira da década de 1990. O Brasil da passagem da década de 1980 para 1990 e, especialmente a partir de 1990, é marcado por fortes traços neoliberais. Em síntese, os modelos de Estado e suas estruturas são apresentados por Coelho (2012) da seguinte maneira: "no mundo contemporâneo, existem diferentes correntes teóricas que procuram explicar as relações entre Estado e mercado, que se aglutinam em duas visões: a liberal e a marxista" (p.26). Sem adentrar ao debate proposto por Coelho (2012), vê-se que o Brasil procurou refletir a matriz liberal, num esforço de ajuste econômico e fiscal, ocasião em que incluiria na arena pública e política a intensa participação popular, a exemplo do já citado art. 48, Brasil (2000) da Lei de responsabilidade fiscal.

Com efeito, o processo de redemocratização, sacramentado com a eleição do primeiro presidente por meio do voto direto (Fernando Collor de Melo, em 1990), inaugura uma nova fase: abertura de mercado e tentativas de estabilização econômica. No entanto, de forma mais definitiva e apoiada em alicerces neoliberais cada vez mais evidentes é o período de 1994 a 2001 (governo do Presidente Fernando Henrique Cardoso, do Partido da Social Democracia Brasileira - PSDB), que promoveria ampla tentativa de estabilização econômica, intenso processo de privatizações e de diminuição do Estado. A legenda seguinte - o Partido dos Trabalhadores - PT (de 2002 até agosto de 2016) manteria a mesma linha de austeridade macro e microeconômica, entretanto perseguiria de forma mais intensa uma agenda social, com viés intervencionista.

O resultado preliminar deste "novo" Brasil é a consequente percepção da sociedade, de que o Estado deve servir de maneira satisfatória aos seus cidadãos, seja no suprimento de suas demandas, seja no cumprimento das leis. De forma crescente, tal visão vem ganhando campo e espalhando-se pelo Brasil, alcançando municípios como Quissamã/RJ.

Nesta trilha, o Tribunal de Contas do Estado do Rio de Janeiro (TCE-RJ) (2005) pontua o seguinte: "a administração pública, pilar fundamental e estruturante do Estado Democrático traduz uma prioridade da ação de governo" (p.98). Este mesmo documento estabelece, dentre outros, princípios fundamentais para administração pública:

- Garantir os direitos relativos à cidadania;

- Respeito aos princípios legais;

- Agir com rigor e eficácia na aplicação dos recursos públicos; 
- Aproximar o Estado dos cidadãos.

É possível crer que uma sociedade forte advenha de indivíduos fortes, ou seja, supridos em suas necessidades, sendo este um movimento contínuo, donde as áreas não satisfeitas tenderão a cumprir a função de agentes motivadores.

Neste cenário, os recursos públicos bem aplicados e geridos democraticamente, funcionariam não só como redutores das desigualdades sociais, mas também como alavancas para o desenvolvimento humano. Assim, para municípios abastecidos pelos royalties, a realidade local tenderia a ser privilegiada, ou seja, com níveis elevados de desenvolvimento humano, social e econômico. No entanto, o que de fato vem se verificando por estudos mais gerais, na prática, como salienta Cruz et. al (2013) é que "no aspecto social, a região (considerando o Norte e Noroeste Fluminense) continua apresentando, em alguns casos, o aprofundamento da miséria e exclusão social" (p. 150).

Neste contexto, a grande demanda social que hoje se apresenta, não só em Quissamã, diz respeito às desigualdades sociais. Os grandes volumes de recursos arrecadados com petróleo, que alavancam o PIB e dinamizam a economia, parecem não ser capazes de debelar as crises sociais. Na visão de Santos (2012) nota-se:

\begin{abstract}
Muitos países como o Brasil não são pobres, mas são tão desiguais que apesar de apresentarem importante evolução de seu PIB (Produto Interno Bruto) e significativas melhorias das condições de vida de alguns, permanecem abrigando uma enorme quantidade de pobres, que, por sua vez, têm baixíssimas perspectivas de mobilidade ascendente (p.19).
\end{abstract}

Mas é preciso cautela ao se analisar isoladamente os números da arrecadação de royalties e os índices de crescimento, pois é possível ceder à ideia de que maiores recursos, na verdade, podem levar a um crescimento menor. A busca por melhores resultados, amplamente perseguida pela iniciativa privada, tem chegado às baias da administração pública, seja pela incidência dos órgãos de fiscalização ou via pressão popular. Esse desejo por resultados mais convincentes é expresso por Falconi. (2009) da seguinte forma:

\begin{abstract}
A vitória de uma organização, seja ela uma escola, um hospital, uma prefeitura, uma empresa ou até mesmo o Governo Federal, é algo desejado por todos e, quando acontece, é uma grande fonte de alegria e satisfação. É fato amplamente conhecido que, alcançar bons resultados é uma das maiores fontes de motivação humana (p. 3).
\end{abstract}

Esse mesmo autor sinaliza que dentre as possíveis causas para os maus resultados estão: a não identificação correta dos problemas; ausência de planejamento; execução distorcida do planejamento.

Com relação ao planejamento cabe destacar que os Governos dispõem de três mecanismos legais com vistas à elaboração de seus planos: o Plano Plurianual; a Lei de Diretrizes Orçamentárias e a Lei Orçamentária Anual. Em Brasil (1988), o art. 165 dispõe sobre o conteúdo do Plano Plurianual - PPA $\left(\$ 1^{\circ}\right)$ - que diz que o PPA estabelecerá, de forma regionalizada, as diretrizes, objetivos e metas da administração pública para as despesas de capital e outras delas decorrentes e programas de duração continuada. 
Vê-se, a partir desse dispositivo, que o PPA cumpre papel específico e determinante na construção de políticas públicas voltadas para sociedade, além de estabelecer vínculos com as demais peças do planejamento público. Assim, alguns objetivos são evidentes:

a) Definição de metas e prioridades;

b) Organizar, em programas, as ações que serão implementadas;

c) Nortear a alocação de recursos nos orçamentos anuais;

d) Facilitar o gerenciamento das ações a serem desenvolvidas;

e) Dar transparência à aplicação de recursos;

f) Estabelecer relação com as demais peças orçamentárias.

Tal instrumento de planejamento, se bem construído, pode atenuar as falhas de gestão apontadas por Falconi (2009), revertendo os precários resultados obtidos no âmbito da administração pública. Como bem destaca Santos (2012):

Gestão pública é a arte de planejar, organizar, coordenar, comandar e controlar assuntos de interesse coletivo por meio da mobilização de estruturas e recursos do Estado. Ela visa, fundamentalmente, garantir o bem estar da comunidade, zelando pela manutenção dos bens e serviços públicos e pelo enfrentamento de situações consideradas problemáticas pelos cidadãos (p.15).

Ainda percorrendo a necessidade do planejamento público e certos de que a realidade brasileira e, portanto, também do município de Quissamã é marcada por graves problemas sociais e que, assim sendo, a ação do Estado deveria estar voltada para o atendimento das demandas emanadas da sociedade, surge o seguinte questionamento: como tornar, de fato, os instrumentos de planejamento da gestão pública, em mecanismos que reflitam os anseios da população? Essa pergunta começa a ser respondida através do conceito de Orçamento Participativo, apresentado em estudos postulados por Reis e Fontes (2002) e Santos (2012).

Depreende-se das análises desses autores que o orçamento participativo surge como experiência relativamente nova e contrapõe-se a prática tradicional, até então muito utilizada, de se preparar o orçamento dentro das salas das repartições públicas. No âmbito do orçamento participativo, geralmente, a inserção popular é garantida através do desenvolvimento de fóruns e formação de conselhos. Assim, Governo e sociedade se reúnem sistematicamente para discutir, avaliar e definir as prioridades das ações para alocação de recursos públicos.

Nesses fóruns são permitidos amplos debates para os valores apresentados para a receita e para despesa, tendo como balizadores a situação atual de cada região e a situação desejada. Deve-se levar em conta, sobretudo, as discussões sobre novos investimentos, bem como a alocação de recursos para atividades de manutenção e custeio dos serviços públicos.

A partir desses debates e situações levantadas, o Governo pode se preparar para elaborar seus planos de ação: Plano Plurianual; Lei de Diretrizes Orçamentárias e Lei Orçamentária Anual (PPA, LDO e LOA). Evidentemente, que os preceitos legais pertinentes a cada um desses instrumentos, consagrados na legislação, Brasil (1964) e Brasil (2000) e especialmente, em Brasil (1988), deverão ser considerados e seguidos. 
Assim sendo, um aspecto positivo do Orçamento Participativo é oferecer oportunidade à comunidade para que esta se manifeste e opine sobre sua própria realidade, exercendo papel determinante não só para a construção da agenda pública local, mas para que esta, sobretudo, reflita a realidade de cada região.

Posto isto, torna-se oportuna a formação de uma agenda política que permita ampla discussão, efetiva análise e a necessária democratização dos recursos petrolíferos. Para tanto, é preciso entender os ciclos políticos e a maneira como a arena pública pode fornecer elementos essenciais para o aperfeiçoamento das práticas de gestão pública. Para Rua (2012):

\begin{abstract}
A correta compreensão do ciclo das políticas públicas pode ser de grande valia para o gestor, favorecendo seu entendimento correto do processo das políticas públicas e auxiliando-o a refletir com clareza sobre como e mediante que instrumentos as políticas poderão ser aperfeiçoadas (p. 35).
\end{abstract}

Em vista do já apresentado e pelas fontes de pesquisas disponíveis descortina-se um horizonte de possibilidades e de análises pertinentes ao contexto de recebimento das verbas do petróleo, bem como dos níveis de desenvolvimento alcançado pelo município de Quissamã, na medida em que se entrecruzam ideias, abordagens, autores e outros que, direta ou indiretamente, participam do debate.

\title{
3. Procedimento Metodológico
}

Segundo Hoffman (2006, p. 15) "o processo metodológico consiste na definição das técnicas e instrumentos que auxiliam na investigação científica". Como já salientado, o presente trabalho envolve revisão bibliográfica, análise quantitativa e pesquisa a documentos públicos da prefeitura do município de Quissamã.

Ressalta-se ainda que toda e qualquer pesquisa deve selecionar dados e através deles definir uma trajetória para a pesquisa. Quando o universo de dados é muito grande, é preciso retirar da população uma amostra que represente-a.

No caso desta pesquisa, seu processo de construção ou ponto de partida foi marcado por pesquisa exploratória visando identificar no material selecionado o problema proposto, apontando possíveis motivos para a existência do mesmo. Quanto a coleta dos dados, a mesma se deu através de buscas a livros e sites sobre o assunto. Foram feitas revisões em relatórios, balancetes, planilhas, gráficos e legislações, entre outras ferramentas necessárias ao desenvolvimento desta pesquisa. Foram acessados sites que abordam o assunto de modo a extrair dados que embasassem a pesquisa, como o Instituto Brasileiro de Geografia e Estatística.

Para formulação do artigo, foram utilizadas informações que retratam a realidade fiscal e/ou de desenvolvimento socioeconômico do município. Portanto, foram consultados órgãos oficiais como a prefeitura local, institutos como o TCE-RJ, IBGE, IPEA e Sebrae-RJ. Além, evidentemente, de trazer à cena autores que debatem o desenvolvimento na região.

\section{Desenvolvimento}

\subsection{Royalties - breve histórico}


É fato que o município de Quissamã recebe elevadas parcelas de royalties do petróleo. Neste sentido, cumpre esclarecer o exato significado desse termo e o quanto, objetivamente, a cidade arrecadou no período analisado por este artigo, ou seja, de 2004 a 2013. Já foi mencionado que tal período foi escolhido por representar certa regularidade no recebimento das verbas, como também por estarem disponíveis as informações quanto aos indicadores de desempenho econômico-social.

A expressão "royalties"- um anglicismo - refere-se a uma compensação financeira devida pelos concessionários de exploração e produção de petróleo, a ser paga mensalmente pelas empresas aos Municípios, Estados e União, amparados pela legislação vigente. Não faz parte do esforço deste artigo estabelecer perspectivas históricas mais aprofundadas no que diz respeito às regras de recebimento dos royalties, tampouco evidenciar o processo evolutivo que culminou nas atuais regras de distribuição. Mas, vale ressaltar a importância da Brasil (1997) chamada de "Lei do Petróleo". Sua principal função, além de manter os critérios de distribuição da Lei anterior, Brasil (1989) foi a de aumentar a alíquota básica para pagamento das indenizações (que passou a ser de $10 \%$ ). Outra alteração importante foi a de que os repasses passariam a ser feitos através da Secretaria do Tesouro Nacional, via Banco do Brasil, fato que vem permitindo maior controle social dos gastos. Também é importante destacar que o município recebe, trimestralmente, uma parcela adicional de royalties, chamada de participação especial. Este recurso, regulamentado pelo Decreto n. ${ }^{\circ}$ 2.705, Brasil (1998), incrementou, ainda mais, os volumes de recursos recebidos.

A chegada de novos marcos regulatórios, tais como da descoberta de novos poços de petróleo e as altas cotações do produto no mercado internacional, permitiram um crescimento exponencial das receitas do município. Tal realidade é o que se segue no próximo tópico.

\subsection{A realidade fiscal de Quissamã em face dos royalties}

A Tabela 2 revela que o município de Quissamã passou a receber, de forma crescente, recursos de royalties entre os anos de 2004 e 2008. Somente em 2009, em função da crise econômica internacional ocorrida em 2008, há uma interrupção na curva de crescimento. Já a partir de 2010, o ritmo de crescimento é retomado, com leve queda em 2013. Os números apresentam que o município recebeu uma média anual de $\mathrm{R} \$$ 74.183.178,44, somente de recursos da parcela mensal da indenização a que faz jus. A receita total média para o período foi de $\mathrm{R} \$ 185.349 .933,38$, levando o município ao expressivo valor de $\mathrm{R} \$$ 1.853.499.333,83 em dez anos de arrecadação. Observa-se, também, que os royalties respondiam por cerca de $40 \%$ das entradas financeiras. 
Tabela 2 - Royalties recebidos entre $2004-2013$

\begin{tabular}{c|r|r|r|r}
\hline \multirow{2}{*}{ PERÍODO } & $\begin{array}{c}\text { TOTAL } \\
\text { ANUAL } \\
\text { ROYALTIES }\end{array}$ & $\begin{array}{c}\text { MÉDIA } \\
\text { MENSAL }\end{array}$ & $\begin{array}{c}\text { RECEITA } \\
\text { TOTAL }\end{array}$ & $\begin{array}{c}\text { \% } \\
\text { ROYALTIES } \\
\text { / RECEITA }\end{array}$ \\
\hline $\mathbf{2 0 0 4}$ & $46.883 .615,26$ & $3.906 .967,94$ & $119.976 .346,90$ & $39,08 \%$ \\
\hline $\mathbf{2 0 0 5}$ & $53.150 .769,74$ & $4.429 .230,81$ & $122.578 .770,83$ & $43,36 \%$ \\
\hline $\mathbf{2 0 0 6}$ & $67.609 .953,83$ & $5.634 .162,82$ & $135.813 .678,86$ & $49,78 \%$ \\
\hline $\mathbf{2 0 0 7}$ & $77.805 .114,72$ & $6.483 .759,56$ & $187.625 .381,14$ & $41,47 \%$ \\
\hline $\mathbf{2 0 0 8}$ & $101.087 .737,47$ & $8.423 .978,12$ & $227.399 .273,45$ & $44,45 \%$ \\
\hline $\mathbf{2 0 0 9}$ & $65.997 .853,12$ & $5.499 .821,09$ & $168.956 .039,61$ & $39,06 \%$ \\
\hline $\mathbf{2 0 1 0}$ & $72.648 .534,65$ & $6.054 .044,55$ & $190.871 .667,36$ & $38,06 \%$ \\
\hline $\mathbf{2 0 1 1}$ & $79.023 .143,96$ & $6.585 .262,00$ & $212.608 .348,01$ & $37,17 \%$ \\
\hline $\mathbf{2 0 1 2}$ & $91.786 .974,90$ & $7.648 .914,58$ & $242.225 .633,65$ & $37,89 \%$ \\
\hline $\mathbf{2 0 1 3}$ & $85.838 .086,74$ & $7.153 .173,90$ & $245.444 .194,02$ & $34,97 \%$ \\
\hline TOTAIS & $\mathbf{7 4 1 . 8 3 1 . 7 8 4 , 3 9}$ & - & $\mathbf{1 . 8 5 3 . 4 9 9 . 3 3 3 , 8 3}$ & $\mathbf{4 0 , 0 2 \%}$ \\
\hline MÉDIA & $\mathbf{7 4 . 1 8 3 . 1 7 8 , 4 4}$ & - & $\mathbf{1 8 5 . 3 4 9 . 9 3 3 , 3 8}$ & $\mathbf{4 0 , 0 2 \%}$ \\
\hline
\end{tabular}

Fonte: Elaboração própria - sistemas de contabilidade da Prefeitura de Quissamã/RJ, 2013.

A Tabela 3 traz informações quanto à participação especial, ou seja, espécie de bônus pago pelos concessionários em função da alta lucratividade de alguns poços de petróleo. Esse dinheiro extra é repassado pela Secretaria do Tesouro Nacional (STN), através do Banco do Brasil, trimestralmente, ou seja, nos meses de fevereiro, maio, agosto e novembro. Constata-se, especialmente, que nos anos de 2007 e 2008 o município de Quissamã recebeu recursos da ordem de R \$ 11,2 milhões e R $\$ 12,5$ milhões, respectivamente, na média trimestral.

Tabela 3 - Participação Especial de Royalties recebidos entre 2004 - 2013

\begin{tabular}{c|c|c|c|r}
\hline PERÍODO & $\begin{array}{c}\text { TOTAL ANUAL } \\
\text { ROYALTIES }\end{array}$ & $\begin{array}{c}\text { MÉDIA } \\
\text { TRIMESTRAL }\end{array}$ & $\begin{array}{c}\text { RECEITA } \\
\text { TOTAL }\end{array}$ & $\begin{array}{c}\text { \% } \\
\text { ROYALTIES } \\
\text { / RECEITA }\end{array}$ \\
\hline $\mathbf{2 0 0 4}$ & $17.843 .378,20$ & $4.460 .844,55$ & $119.976 .346,90$ & $14,87 \%$ \\
\hline $\mathbf{2 0 0 5}$ & $22.124 .260,77$ & $5.531 .065,19$ & $122.578 .770,83$ & $18,05 \%$ \\
\hline $\mathbf{2 0 0 6}$ & $17.190 .788,10$ & $4.297 .697,03$ & $135.813 .678,86$ & $12,66 \%$ \\
\hline $\mathbf{2 0 0 7}$ & $45.126 .187,95$ & $11.281 .546,99$ & $187.625 .381,14$ & $24,05 \%$ \\
\hline $\mathbf{2 0 0 8}$ & $50.398 .783,91$ & $12.599 .695,98$ & $227.399 .273,45$ & $22,16 \%$ \\
\hline $\mathbf{2 0 0 9}$ & $25.869 .635,30$ & $6.467 .408,83$ & $168.956 .039,61$ & $15,31 \%$ \\
\hline $\mathbf{2 0 1 0}$ & $19.984 .631,14$ & $4.996 .157,79$ & $190.871 .667,36$ & $10,47 \%$ \\
\hline $\mathbf{2 0 1 1}$ & $13.589 .804,84$ & $3.397 .451,21$ & $212.608 .348,01$ & $6,39 \%$ \\
\hline $\mathbf{2 0 1 2}$ & $15.337 .564,44$ & $3.834 .391,11$ & $242.225 .633,65$ & $6,33 \%$ \\
\hline $\mathbf{2 0 1 3}$ & $11.260 .410,77$ & $2.815 .102,69$ & $245.444 .194,02$ & $4,59 \%$ \\
\hline TOTAIS & $\mathbf{2 3 8 . 7 2 5 . 4 4 5 , 4 2}$ & - & $\mathbf{1 . 8 5 3 . 4 9 9 . 3 3 3 , 8 3}$ & $\mathbf{1 2 , 8 8 \%}$ \\
\hline MÉDIA & $\mathbf{2 3 . 8 7 2 . 5 4 4 , 5 4}$ & - & $\mathbf{1 8 5 . 3 4 9 . 9 3 3 , 3 8}$ & $\mathbf{1 2 , 8 8 \%}$ \\
\hline
\end{tabular}

Fonte: elaboração própria - sistemas de contabilidade da Prefeitura de Quissamã, 2013.

As informações contidas na Tabelas 2 e na Tabela 3 revelam que os royalties correspondem cerca de $53 \%$ das receitas gerais. Assim, é fácil demonstrar a 
dependência fiscal do município em relação a tais receitas. Também é de conhecimento da população local e das autoridades constituídas que outros $30 \%$ da arrecadação provém da arrecadação do imposto sobre circulação de mercadorias e serviços (ICMS), sobretudo das atividades da cadeia do petróleo na região, gerando um quadro de dependência de aproximadamente $80 \%$ em relação às transferências constitucionais.

A abundância de recursos permitiu ao poder público local dinamizar e diversificar a economia doméstica. Na primeira década dos anos 2000 houve a instalação da primeira zona especial de negócios (ZEN1). Por meio dela e de seus incentivos fiscais, algumas empresas foram atraídas para o município, tais como: fábrica de laticínios Macuco, DM metalurgia, dentre outras. Mesmo que timidamente, o número de empregos cresceu aquecendo toda a economia local. Neste mesmo período, iniciouse na localidade de Barra do Furado, o projeto de instalação de um estaleiro naval, cuja dimensão e frutos ainda não são percebidos pela população local.

Todavia, a escala de atração de novas empresas e de diversificação econômica nunca ocorreu na proporção do aumento das receitas, ou seja, da capacidade de investimentos do poder público. $\mathrm{Na}$ verdade, foram se fortalecendo políticas de transferência de renda; aumento dos gastos com o funcionalismo e com subsídios, trazendo uma clara preocupação com o chamado custeio da máquina pública. Este sim, em trajetória de expansão, vem limitando a capacidade de crescimento local e impedindo ações mais estruturantes por parte do governo. Não há dúvida que as riquezas do petróleo permitiram a construção de hospitais, novas escolas, aumento da malha de saneamento e o alargamento das ações públicas. Entretanto, isso em nada sinaliza sobre a qualidade do gasto, nem permite análise comparativa e qualitativa da realidade social local. Essa investigação se dará nos próximos tópicos.

\subsection{O desenvolvimento social de Quissamã}

Foram escolhidos três índices de desenvolvimento econômico/social, a fim de apurar o quanto os fartos recursos recebidos pelo município lhe permitiram alcançar novos patamares de desenvolvimento. Tais indicadores são: índice de desenvolvimento da educação básica (Ideb); índice de desenvolvimento humano (IDH) e o índice de distribuição de renda (índice de Gini). A apresentação desses indicadores ocorrerá comparativamente à realidade do município vizinho de Conceição de Macabu, considerando que este município mantém perfil demográfico similar ao de Quissamã, mas não recebe royalties nos mesmos patamares.

Segundo o Instituto Nacional de Estudos e Pesquisa (INEP - 2014), o índice de desenvolvimento da educação básica - Ideb é um indicador de qualidade educacional que combina informações de desempenho em exames padronizados. Este tipo de indicador permite o monitoramento do sistema de ensino no país. Sua importância está associada à possibilidade de diagnóstico quanto à qualidade da educação básica, permitindo o norteamento das ações políticas para melhoria do ensino público. A realidade de Quissamã está assim descrita: 
Tabela 4 - Análise comparada do IDEB entre 2005 - 2011

\begin{tabular}{l|c|c|c|c}
\multirow{2}{*}{ Períodos } & \multicolumn{2}{|c|}{ Quissamã } & \multicolumn{2}{c}{ Conceição de Macabu } \\
\cline { 2 - 5 } & $\mathbf{4}^{\mathrm{a}}$ série & $\mathbf{8}^{\mathrm{a}}$ série & $\mathbf{4}^{\mathbf{a}}$ série & $\mathbf{8}^{\mathbf{a}}$ série \\
\hline 2005 & $\mathbf{3 . 2}$ & $\mathbf{3 . 4}$ & $\mathbf{3 . 7}$ & $\mathbf{4 . 0}$ \\
\hline 2007 & $\mathbf{4 . 5}$ & $\mathbf{2 . 9}$ & $\mathbf{4 . 7}$ & $\mathbf{3 . 7}$ \\
\hline 2009 & $\mathbf{4 . 3}$ & $\mathbf{3 . 7}$ & $\mathbf{4 . 8}$ & $\mathbf{3 . 7}$ \\
\hline 2011 & $\mathbf{5 . 1}$ & $\mathbf{3 . 8}$ & $\mathbf{4 . 7}$ & $\mathbf{3 . 9}$ \\
\hline Média & $\mathbf{4 . 2 8}$ & $\mathbf{3 . 4 5}$ & $\mathbf{4 . 4 8}$ & $\mathbf{3 . 8 3}$
\end{tabular}

Fonte: Elaboração própria - com informações do portal IDEB, 2011.

Tomando-se a Tabela 4, comparativamente, o município de Conceição mesmo não recebendo os recursos do petróleo que Quissamã, tem desempenho médio melhor, independente da série observada ( $4^{\mathrm{a}}$ ou $8^{\mathrm{a}}$ séries). Somente em 2011 é que Quissamã desponta com desempenho considerado satisfatório (5.1 - para as séries iniciais). Dados do MEC (Ministério da Educação e Cultura) revelam que em 2011 Quissamã estava na posição 2.145, entre os mais de cinco mil municípios do Brasil, considerando o resultado dos anos iniciais ( $4^{\mathrm{a}}$ série). Já no caso dos alunos da $8^{\mathrm{a}}$ série (anos finais) a posição obtida foi a de 2.961. Já Conceição de Macabú, com renda bem inferior, em 2011 ocupou a posição 2.839 para os anos iniciais e a posição 2.706, no caso dos alunos concluintes ( $8^{\mathrm{a}}$ série). Segundo o MEC, um dado a se lamentar, de maneira geral, é que em 2011 somente 711 municípios brasileiros obtiveram notas superiores a 6,0. Isto considerando apenas os anos iniciais de estudo ( $4^{\mathrm{a}}$ série). Tomando a nota dos alunos da $8^{\mathrm{a}}$ (anos finais), apenas 10 municípios brasileiros alcançaram notas superiores a 6,0. Esta nota foi facilmente batida por instituições particulares.

Já o IDHM (Índice de Desenvolvimento Humano Municipal) idealizado pela ONU e calculado com base em informações do IBGE tem por finalidade apresentar um indicador de desenvolvimento mais completo. Assim, o IDHM leva em consideração aspectos ligados à saúde (longevidade), renda e níveis de educação. Este índice vai de zero a um, sendo que quanto mais próximo de zero, pior o resultado do município. Quanto mais próximo de um, melhor. Neste aspecto, a situação de Quissamã, comparativamente à de Conceição de Macabu, é a seguinte:

- Dados de 2010. IDHM Quissamã, 0,704. Este valor está na faixa de desempenho considerada alta $(0,700-0,799)$, porém no limiar da faixa considerada de médio desenvolvimento humano $(0,600-0,699)$. Com esse índice, o município ocupa a posição $\mathbf{1 . 7 7 6}$ no ranking nacional.

-Dados de 2010. IDMH Conceição de Macabu, 0,712. Este valor está na faixa de desempenho considerada alta $(0,700$ - 0,799), já um pouco mais distante da faixa de médio desenvolvimento. Conceição ocupa a posição $\mathbf{1 . 5 4 6}$ no ranking nacional.

Segundo o Instituto de Pesquisa Econômica Aplicada (IPEA) (2014), o chamado índice de Gini, criado pelo matemático italiano Conrado Gini, é um instrumento para medir o grau de concentração de renda em determinado grupo. Ele aponta a diferença entre os rendimentos dos mais pobres e dos mais ricos. Numericamente, varia de zero a um (alguns apresentam de zero a cem). $\mathrm{O}$ valor zero representa a situação de igualdade, ou seja, todos têm a mesma renda. O valor um (ou cem) está no extremo oposto, isto é, 
uma só pessoa detém toda a riqueza. Na prática, o Índice de Gini costuma comparar os $20 \%$ mais pobres com os $20 \%$ mais ricos.

As informações obtidas comprovam que a concentração de renda vem crescendo em Quissamã. A participação dos $20 \%$ mais pobres da população na renda, isto é, os que ficam com apenas $20 \%$ da riqueza produzida passou de 3,60\% em 1991, para 3,87\% em 2010, ou seja, aumentou a fatia dos pobres e os níveis de desigualdade. Por outro lado, a participação dos ricos aumentou 15,11 superior à dos $20 \%$ mais pobres.

O município vizinho, Conceição de Macabú, conseguiu reduzir suas desigualdades. A participação dos $20 \%$ mais pobres, ou seja, dos que ficam com apenas $20 \%$ das riquezas produzidas pelo município, passou de $4,10 \%$ em 1.991 , para $3,84 \%$, em 2.010, diminuindo, assim, os níveis de desigualdade. Por outro lado, a participação e representatividade dos 20\% mais ricos também diminuíram. Cabe destacar que em 2010, o índice apurado para Quissamã foi de 0,54 , aparecendo na posição $73^{\mathrm{a}}$ do ranking estadual. Lembrando que o Estado do Rio conta com 92 municípios. Já Conceição atingiu a posição $31^{\mathrm{a}}$ no ranking estadual e $2.176^{\mathrm{a}}$ no nacional.

\subsection{Alguns problemas contemporâneos}

A exemplo de boa parte dos municípios brasileiros, Quissamã convive com carências expressivas, tanto no nível das necessidades básicas, quanto nas oportunidades de ascensão social. Relatórios internos da Secretaria de Desenvolvimento Econômico do município, indicam a existência de déficits habitacionais, de falta de mão de obra qualificada para atender demandas específicas e de aumento da violência urbana e rural. Além disso, parecem ainda não resolvidos problemas relacionados ao fornecimento de água, ao transporte público e a criação de empregos formais. $\mathrm{O}$ município que no passado abrigara importante centro de produção de cana-de-açúcar, vê sua vocação agrícola direcionada, numa escala ainda tímida, à produção de coco.

Sabe-se que atualmente o maior empregador é poder público, sendo este o principal dinamizador da economia local. Pelas potencialidades turísticas, tanto ligadas aos recursos naturais quanto ao conjunto arquitetônico que o município dispõe, ainda parecem tímidas as iniciativas do poder público para, efetivamente, promover o desenvolvimento da região. Por ser considerado um município rico (pelas divisas do petróleo que recebe) atrai mão de obra pouco qualificada, que não encontrando emprego, fica à margem das oportunidades e, ainda pior, na dependência do poder público. Assim, parecem evidentes problemas recorrentes aos grandes centros a despeito dos grandes volumes de recursos que potencialmente poderiam garantir novos patamares de desenvolvimento.

\subsection{Mecanismos de controle social}

De forma geral, os conselhos de controle social ganharam papel decisivo na agenda política nacional com a promulgação da Constituição Federal de 1988 (Brasil, 1988), que estabeleceu novas dimensões para os direitos individuais e coletivos. O Controle em áreas estratégicas como Saúde e Educação, ocorre via conselhos municipais, que exercem funções deliberativas, consultivas e fiscalizatórias. Obviamente que muitas outras demandas chegam às barras dos conselhos. Todavia, sendo a Lei Orçamentária Anual apenas autorizativa, muitos dos debates promovidos no 
âmbito desses conselhos, ainda que canalizados para a Lei Orçamentária, ficam a mercê da vontade política para serem levados às vias de fato.

Só mais recentemente a câmara de vereadores local criou uma comissão parlamentar especial para acompanhamento, fiscalização e aplicação dos recursos dos royalties, como forma de democratizar e de debater os rumos da cidade e as decisões políticas. Com efeito, a participação popular ainda é restrita. Apesar de perceberem em sua realidade prática os problemas que a cidade enfrenta, os cidadãos se mantêm a distância das arenas que debatem os temas públicos. As audiências convocadas tanto pelo executivo quanto pelo legislativo, para prestação de contas e esclarecimentos à população, recebem tímidas participações. Neste sentido, muito ainda precisa ser feito no que se refere à democratização e ampliação das discussões que visem ao aperfeiçoamento da cidadania e do desenvolvimento local.

\section{Conclusões}

Este estudo estabeleceu um paralelo entre os altos recebimentos de recursos do petróleo e a realidade socioeconômica do município de Quissamã. Um município rico em receitas e, por adição, com baixa densidade populacional deveria alcançar níveis de desenvolvimento superiores àqueles encontrados, por exemplo, em outros municípios, com semelhanças populacionais e territoriais.

O que se verificou, ainda que de forma preliminar, é que os recursos do petróleo permitiram alguns avanços na condição de vida da população, tais como: aumento na atração de emprego formal e aumento da infraestrutura e dos equipamentos públicos (postos de saúde, quadras poliesportivas, praças, museus e etc.). Além disso, fortaleceram-se iniciativas e políticas de transferência de renda, conjuntamente aos subsídios públicos. Todavia, chamou à atenção a percepção local de que o dinheiro público não vem gerando benefícios mais estruturantes que permitam, inclusive, que o município se torne independente dos recursos do petróleo.

O levantamento do índice de Gini, por exemplo, mostrou que a concentração de renda vem aumentando, levando o município à incômoda posição de $73^{\circ}$ no ranking estadual, que é totalizado por 92 municípios. Com relação ao Índice de Desenvolvimento da Educação Básica IDEB, os dados também mostraram que o município de Conceição de Macabu, apesar de não receber recursos do petróleo, sempre esteve à frente de Quissamã. Tal questão revela que o problema pode estar relacionado não a quantidade de recursos recebidos, mas a qualidade do gasto público. Também ficou evidente a ausência de canais mais efetivos que ajudem a promover a participação popular na administração e na destinação dos recursos dos royalties. Nesta concepção, esta participação é ainda restrita, seja por desinteresse da comunidade local ou pela completa ausência de espaços públicos, de arenas que de fato absorvam, de forma direta, as indicações da sociedade.

Por fim, este estudo pode ser ampliado, seja no aprofundamento dos assuntos aqui propostos ou mesmo na consulta comparativa com outros municípios e com outros índices de desenvolvimento. Não se pode ter a impressão de que os recursos gerados pelos royalties sejam uma herança maldita.

Assim, novos esforços poderão ser feitos, inclusive com pesquisas empíricas, que nos levem por caminhos alternativos e buscando sempre, à luz do conhecimento científico, propostas que visem o amadurecimento e aperfeiçoamento das sociedades. 


\section{Referências Bibliográficas}

Brasil (1964). Lei $n^{o}$ 4320. Institui Normas Gerais de Direito Financeiro para Elaboração e Controle dos Orçamentos e Balanços da União, Estados, dos Municípios e do Distrito Federal. Diário Oficial da União, Brasília, DF, 23 mar. 1964.

Brasil (1988). Constituição da República Federativa do Brasil. Brasília, DF: Senado.

Brasil (1989). Lei no 7990. Institui, para os Estados, Distrito Federal e Municípios, compensação financeira pelo resultado da exploração de petróleo e gás natural. Oficial da União, Brasília, DF, 28 fev. 1989.

Brasil (1997). Lei no 7478. Dispõe sobre a política energética nacional. Oficial da União, Brasília, DF, 06 ago. 1997.

Brasil (1998). Decreto $\mathrm{n}^{\circ}$ 2705. Define critérios para cálculos e cobrança das participações governamentais. Oficial da União, Brasília, DF, 03 ago. 1998.

Brasil (2000). Lei Complementar, $n^{o}$ 101, 4 maio. Brasília, DF: Senado.

Coelho, R.C. (2012). Estado, governo e mercado. 2. ed. Brasília: CAPES:UAB.

Cruz, F., Vicari Junior, A., Glock, J.O., Herzmann, N. \& Temel, R. (2006). Lei de Responsabilidade Fiscal Comentada, $5^{\text {a }}$ ed. São Paulo: Atlas.

Cruz, J. L., Piquet, R. \& Vilani, R.M. (org). (2013). O desafio da abundância: 10 anos do boletim do petróleo royalties e região, $1^{\mathrm{a}}$ ed. Rio de Janeiro: Garamond.

Falconi, V. (2009). O verdadeiro poder: práticas de gestão que conduzem a resultados revolucionários. Nova Lima: INDG Tecnologia e Serviços Ltda.

Fontes, A. M. M \& Reis, H. C. (2002) Orçamento Público e Desenvolvimento Local. Rio de Janeiro: IBAM/DES/NEL.

Hoffman, J. (2006). Manual para elaboração e normatização de trabalhos científicos. Itaperuna (RJ): FIPH.

Instituto Brasileiro de Geografia e Estatística (2013, Junho). Web site: http://www.cidades.ibge.gov.br.Disponível em <http://www.ibge.gov.br/cidadesat/topwindow.htm?1>. Acesso em 07.Jun.2013.

Instituto de Pesquisa Econômica Aplicada, IPEA (2014, Janeiro). Web site: http://www.ipea.gov.br. Disponível em: http://www.ipea.gov.br/portal/ Acesso em 16 Jan. 14. 
Instituto Nacional de Estudos e Pesquisas Educacionais Anísio Teixeira, INEP (2014, Fevereiro). Disponível em: http://portal.inep.gov.br/web/portal-ideb acesso em $07 / 02 / 14$

Rua, M. G. (2012) Políticas Públicas, 2a ed. Florianópolis: Departamento de Ciências da Administração/ UFSC.

Santos, M. P. G. (2012). O Estado e os Problemas Contemporâneos, $2^{\mathrm{a}}$ ed, Florianópolis: Departamento de Ciências da Administração/ UFSC.

Santos, R. C. L. F. (2012). Plano Plurianual e Orçamento Público. 2. ed. Brasília: CAPES/UAB.

Tribunal de Contas do Estado do Rio de Janeiro (2002). Estudo Sócio-Econômico 19972001 Quissamã-RJ. Rio de Janeiro: TCE.

Tribunal de Contas do Estado do Rio de Janeiro (2005). Planejamento e Gestão das Ações de Governo. Rio de Janeiro: TCE. 